\title{
Erk1/2, CDK8, Src and Ck1e Mediate Evodia rutaecarpa Induced Hepatotoxicity in Mice
}

\author{
Wenqiang Liao1,2*, Bo Li ${ }^{*}$, Li Li1 ${ }^{1}$, Liangchun Yan1, Zhou Wang1, Xiaojuan An1, \\ Junning Zhao"\# \\ ${ }^{1}$ Sichuan Academy of Chinese Medicine Sciences, Chengdu, China \\ ${ }^{2}$ Internal Medicine, Henry Ford Health System, Detroit, USA \\ Email: "zarmy@189.cn
}

Received 6 March 2015; accepted 9 May 2015; published 14 May 2015

Copyright (C) 2015 by authors and Scientific Research Publishing Inc. This work is licensed under the Creative Commons Attribution International License (CC BY). http://creativecommons.org/licenses/by/4.0/

\section{c) (i) Open Access}

\begin{abstract}
Evodia rutaecarpa (E.R.) is a commonly used Chinese herbal medicine. However, it exerts certain hepatotoxicity and the underlying molecular mechanism has not been clarified. In this study, we investigated the molecular mechanism involved in hepatotoxicity induced by E.R. Mice were treated with E.R. water- and ethanol-extract at dosage equivalent to $16.67 \mathrm{~g}$ crude-drug/kg body weight by intragastric administration once a day on 30 consecutive days. The effect of E.R. extract on liver, manifested by histopathologic effects, liver index, and blood biochemical indexes were tested. In addition, interleukin (IL)-1 $\beta$, IL-6, IL-8, and tumor necrosis factor (TNF)- $\alpha$ in liver tissue were measured. The signaling transduction molecules were determined by antibody microarray assay, and verified by western blot. E.R. extract, either water- or ethanol-extract, can induce liver dysfunction. Signaling molecules, Erk1/2, Src, CDK8 and CK1e, were involved in this process. E.R. extract can induce Ck1e expression and phosphorylation of Erk1/2 and CDK8, and inhibit Src phosphorylation. Inflammatory cytokines in liver tissue, IL-1 $\beta$, IL-6, IL-8, and TNF- $\alpha$ were markedly increased upon the treatment of E.R. extract. In conclusion, E.R.-induced hepatotoxicity was due to the expression of inflammatory cytokine, which was mediated through Erk1/2, Src, CDK8 and CK1e.
\end{abstract}

\section{Keywords}

Evodia rutaecarpa, Hepatotoxicity, Cellular Signaling, Antibody Microarray, Inflammatory Cytokines

\footnotetext{
* These two authors equally contributed to this work.

${ }^{\#}$ Corresponding author.
} 


\section{Introduction}

Evodia rutaecarpa (E.R.), first recorded in the ancient medicine book of "Shen Nong's Herbal" with functions of smoothing liver and analgesia, is the dry mature fruit harvested from perfume plants, such as E.R. (Juss) Benth. E.R. is a commonly used Chinese herbal medicine and exerts many beneficial effects, such as analgesia through either inhibition of COX2 or desensitizing sensory nerves [1] [2] and cardiovascular and gastrointestinal protection through either activation of cholecystokinin 1 receptor or transient receptor potential channel vanilloid type $1[3]$ [4].

E.R. exerts various pharmaceutical actions and has been widely used both in clinical practices and in food industry as a dietary supplement. However, toxicity of E.R., especially hepatotoxicity, has been found recently [5] [6]. Recently, we also found that either water- or ethanol-extracts of E.R. could increase the liver index, serum total cholesterol and glutamic-pyruvic transaminase in rats in a dose-dependent manner. The molecular mechanism involved in the E.R.-induced hepatotoxicity has not been clarified yet.

High-throughput proteomics technology has been widely employed to determine biomarkers, including cellular signaling molecules and specific proteins associated with hepatotoxicity [7] [8]. Antibody array, reversephase protein array and peptide assays are most commonly used, and can efficiently determine information about protein-protein interactions, and biomarkers [9]-[11]. Cho and colleagues have successfully identified 10 targeted proteins among 325 distinct proteins potentially related to cisplatin-induced hepatotoxicity by an informatics-assisted label-free protein quantitation together with microarray gene expression approach [12]. Through proteomic and transcriptomic analysis, 8 targeted proteins (FASN, CYP2D1, UG2TB, ALDH1A1, GSTA2, HSP90, FABP4, and ABCB11) among 607 differentially expressed proteins were identified as important biomarkers associated with hepatotoxicity induced by simvastatin [13]. Hu's research team has confirmed 15 liverspecific blood protein markers for acetaminophen-induced hepatotoxicity by antibody microarray [14].

In the present study, hepatotoxicity upon the treatment of mice with water- and ethanol-extracts of E.R. was determined. Potential cellular signaling molecules involved in E.R.-induced hepatotoxicity were investigated through antibody microarray assay, and further verified by western blotting. Some inflammatory cytokines in the liver tissue, such as interleukin (IL)-1 $\beta$, IL-6, IL-8, and tumor necrosis factor (TNF)- $\alpha$, were measured to determine whether or not these factors were involved in the E.R.-induced hepatotoxicity.

\section{Materials and Methods}

\subsection{Evodia rutaecarpa}

E.R., locally named Wu Zhu Yu, was collected in Hong Miao Cun, Nanchuan, Chongqing, China (GPS: $29.330149^{\circ} \mathrm{N}, 106.925874^{\circ} \mathrm{E}$ ). The plant name has been checked with www.theplantlist.org mentioning the data of accessing that website. E.R. extract was prepared according to 2010 version Chinese Pharmacopeia. Briefly, $70 \%$ ethanol or water (10-time weight of E.R.) was used for the first round 90 -min extraction. $70 \%$ ethanol or water (8-time weight of E.R.) was used for the second round 60-min extraction. After filtration, the extract was condensed by evaporating. The extract is thick ointment, and $1 \mathrm{~g}$ water-extract and ethanol-extract is equivalent to $2.32 \mathrm{~g}$ and $3.05 \mathrm{~g}$ crude-drug, respectively.

\subsection{Animals}

Forty-two Kun-Ming mice $(20 \pm 3.3 \mathrm{~g}$, body weight $)$ were purchased from Experimental Animal Center of Sichuan Academy of Chinese Medicine Sciences. On the day of experiment, animals were randomly divided into three groups, with 14 mice in each group. Mice were administered either water- or ethanol-extract of E.R. at a dosage equivalent to $16.67 \mathrm{~g}$ crude- $\mathrm{drug} / \mathrm{kg}$ body weight as determined by our previous study, by intragastric (ig) administration once a day on 30 consecutive days. Mice in the control group were treated by physiological saline. After the last administration, mice were weighed and then anesthetized with $1 \%$ pentobarbital sodium $(0.5$ $\mathrm{ml} / 100 \mathrm{~g}$ body weight, intraperitoneal injection) after fasting 12 hours, and then sacrificed by decapitation. The mouse livers and the blood samples were collected for further experiments. The research was undertaken as required by the Animal Ethics Committee of Sichuan Academy of Chinese Medicine Sciences (Chengdu, China), and was conducted in accordance with the internationally accepted principles for laboratory animal use and care as found in the US guidelines (NIH publication \#85-23, revised in 1985). 


\subsection{Haematoxylin-Eosin Staining (H-E) and Transmission Electron Microscope (TEM)}

4 mice in each group were sacrificed as described above and their livers were taken out and cut into about 4-mm thickness pieces and fixed with a buffered 4\% paraformaldehyde solution. Regular H-E staining was performed for liver morphological observation. For the TEM detection, mouse liver was fixed in 4\% paraformaldehyde solution and then fixed in 1\% osmium tetroxide, followed by gradually dehydrating using acetone solution. Embedded in the Epon812, the sample was cut into about 60-nm thickness slices, double stained with uranium acetate and plumbum citrate and observed with H-600 TEM (HITACH, Japan).

\subsection{Preparation of Total Protein Extract}

4 mice in each group were sacrificed as described above, and then their livers were taken out and washed twice with ice-cold $\mathrm{NaCl} / \mathrm{Pi}$. Livers were cut into pieces and washed twice again, and then homogenized with $1 \mathrm{~mL}$ ice-cold tissue lysis buffer [20 mM MOPS, pH 7.0, $100 \mathrm{mM} \mathrm{NaCl}, 10 \mathrm{mM}$ sodium pyrophosphate, $5 \mathrm{mM}$ EDTA, $2 \mathrm{mM}$ EGTA, $50 \mathrm{mM} \mathrm{NaF}, 1 \mathrm{mM}$ sodium vandate, 0.1\% (w/v) SDS, 10\% (w/v) glycerol, 1\% (v/v) Triton X-100, $1 \%(\mathrm{w} / \mathrm{v})$ sodium deoxycholate] containing protease inhibitors (Halt Protease Inhibitor Cocktail Kit; Pierce Biotechnology, Rockford, IL, USA). Homogenates were sonicated four times for 10 seconds each time with 10 - 15 second intervals on ice and followed by centrifugation at $16,000 \mathrm{~g}$ for $20 \mathrm{~min}$ at $4{ }^{\circ} \mathrm{C}$ and the supernatants were collected for further assay. Protein abundance was determined using the BCA protein assay kit (Pierce Biotechnology, Inc., Rockford, IL, USA).

\subsection{Antibody Chip Analysis}

Cell signaling molecules potentially involved in hepatotoxicity induced by E.R. were investigated using the KAM-850 Antibody Microarray (Kinexus Bioinformatics Corporation, Vancouver, B.C. Canada V6P 6T3) according to the manufacturer's instructions. Briefly, protein samples containing $100 \mu \mathrm{g}$ from the control and the water-extract group were first chemically digested, and then labeled and purified using the dying and purification kit supplied in the Antibody Microarray Kit. A KAM-850 Antibody Microarray chip was blocked for 1 hour in the blocking buffer, followed by incubation with pretreated protein samples for 2 hours in the incubation buffer. The antibody chip was screened at $540 \mathrm{~nm}$ by VersArray ChipReader (Bio-Rad Laboratories, Inc. Hercules, CA 94547, USA). Data were analyzed through the Ingenuity Pathway Analysis (IPA) software (Ingenuity system Inc. QIAGEN Redwood City, CA 94063, USA).

\subsection{Western Blot Detection}

Following protein quantification, $30 \mu \mathrm{g}$ of each protein sample was electrophoresed on a $10 \%$ sodium dodecyl sulphate-polyacrylamide gel, transferred to a nitrocellulose membrane (Pall Corporation, East Hill, NY, USA), immunoblotted with antibodies against phospho-Erk1/2, phospho-Src, phospho-Cdk8 and Ck1e (Cell Signaling Tech., Beverly, MA, USA), and Erk1/2, Src, Cdk8 and $\beta$-actin (Santa Cruz Biotech. CA, USA) according to the supplier's protocol, and visualized with peroxidase and an enhanced-chemiluminescence system (ECL kit, Pierce Biotechnology, Inc.).

\subsection{Enzyme-Linked Immunosorbent Assay (ELISA)}

4 mice in each group were sacrificed and their liver tissue homogenates were obtained. The content of interleukin (IL)-1 $\beta$, IL-6, IL-8 and tumor necrosis factor (TNF)- $\alpha$ was measured in liver tissue homogenates using specific ELISA kits according to the manufacturers' instructions (IL- $1 \beta$ and TNF- $\alpha$ : Pierce Biotechnology, Inc., Rockford, IL, USA.; IL-6 and IL-8: Cusabio Co., Wuhan, CHINA;).

\subsection{Statistic Analysis}

All data are expressed as the mean \pm S.E.M. The statistical significance of differences between two groups was determined by Student's t-test. For 3-group comparisons, data were analyzed by one-way ANOVA followed by Dunnett's test. A p-value $<0.05$ was considered statistically significant. 


\section{Results}

\subsection{E.R. Extract Induces Hepatotoxicity}

The liver index was significantly increased in the E.R. water-extract and ethanol-extract groups compared with the control group (liver index $6.86 \pm 0.47$ in the water-extract group, $6.68 \pm 0.62$ in the ethanol-extract group versus $5.22 \pm 0.51$ in the control group, $\mathrm{p}<0.01, \mathrm{n}=12$, respectively, Table 1). Further, the serum parameters related to liver function, alanine aminotransferase (ALT), aspartate transaminase (AST), triglyceride (TG), total cholesterol (TC) and glucose (GLU) were measured. The level of both ALT and TG in serum were strongly increased in the E.R. water- and ethanol-extract group compared with that in the control group (ALT $148.42 \pm$ $37.87 \mathrm{IU} / \mathrm{L}$ in the water- and $150.69 \pm 97.15 \mathrm{IU} / \mathrm{L}$ in the ethanol-extract group versus $47.85 \pm 24.10 \mathrm{IU} / \mathrm{L}$ in the control group, $\mathrm{p}<0.01$, respectively; TG $2.61 \pm 0.58$ in the water- and $2.57 \pm 0.75$ in the ethanol-extract group versus $1.83 \pm 0.87$ in the control group, $\mathrm{p}<0.05$, respectively, $\mathrm{n}=12$, as shown in Table 2).

In addition, H-E staining was performed to observe the pathomorphological changes, as shown in Figure 1. In the control group, the liver tissues are intact and hepatocytes are eumorphism. In contrast, in the E.R. water- or ethanol-extract group, hepatocytes exhibit swelling and degeneration, and the infiltration of inflammatory cells was observed. In addition, under TEM observation, we found that there were some swelling mitochondria and lipid droplets in the cytoplasm in the E.R. treated groups.

Taking together, these data indicate that either the water- or the ethanol-extracts of E.R. can induce hepatotoxicity in mice.

\subsection{Signaling Molecules Involved in E.R.-Induced Hepatotoxicity}

The signaling molecules involved in E.R.-induced hepatotoxicity were investigated through the antibody microarray chip, as shown in Figure 2(a). Totally, 854 molecules were detected by the antibody microarray assay. According to the criteria of Kinexus Bioinformatics Corporation, significantly-changed molecules must meet the following four conditions concurrently: 1) Z-ratio $\geq \pm 1.0$; 2) \% Error Range $\leq 50$; 3) Globally Normalized Median Value $\geq 618 ; 4$ ) Flags $=0.0$. In addition, proteins were screened for potential involvement in hepatotoxicity using Ingenuity Pathway Analysis. Proteins that were significantly-changed and also listed in the "Increase Liver Damage Report" of the Ingenuity "Tox List Report" are shown in Figure 2(b). To our knowledge, 4 signaling pathways, i.e. the TGF- $\beta / \mathrm{Smad}$, Wnt $/ \beta$-catenin, mTOR and NF $\kappa$-B pathways, have been most commonly reported to be involved in Chinese Medicine-related hepatotoxicity. So, the array results were examined for key signaling molecules in these pathways, as shown in Table 3, and 4 signaling molecules, Erk1/2, Src, CDK8 and CK1e, were identified as molecules potentially involved in E.R.-induced hepatotoxicity.

\subsection{Verification of Antibody Microarray Data by Western Blot Assay}

Western blot assay was used to verify the signaling molecules selected from the antibody microarray chip, as

Table 1. The effect of Evodia rutaecarpa extract on liver index in mice.

\begin{tabular}{cccc} 
& Body weight (g) & Liver weight $(\mathbf{g})$ & Liver index (g/100g body weight) \\
\hline Control & $34.29 \pm 4.61$ & $1.78 \pm 0.23$ & $5.22 \pm 0.51$ \\
Water-extract & $32.62 \pm 3.89$ & $2.24 \pm 0.33^{\#}$ & $6.86 \pm 0.47^{\#}$ \\
Ethanol-extract & $31.85 \pm 3.28$ & $2.14 \pm 0.39^{\#}$ & $6.68 \pm 0.62^{\#}$ \\
\hline
\end{tabular}

All values represent the mean \pm S.E.M. $(\mathrm{n}=12)$. ${ }^{\#} \mathrm{p}<0.01$ compared with control.

Table 2. Evodia rutaecarpa induces hepatotoxicity in mice.

\begin{tabular}{ccccc}
\hline Group & ALT $($ IU/L) & AST (IU/L) & TG (mmol/L) & TC mmol/L) \\
\hline Control & $47.85 \pm 24.10$ & $156.38 \pm 89.62$ & $1.83 \pm 0.87$ & $2.73 \pm 0.35$ \\
Water-extract & $148.42 \pm 37.87^{\#}$ & $183.92 \pm 77.79$ & $2.61 \pm 0.58^{*}$ & $2.59 \pm 0.64$ \\
Ethanol-extract & $150.69 \pm 97.15^{\#}$ & $179.38 \pm 70.56$ & $2.57 \pm 0.75^{*}$ & $2.80 \pm 0.66$ \\
\hline
\end{tabular}

All values represent the mean \pm S.E.M. $(n=12) .{ }^{*} \mathrm{p}<0.05$ and ${ }^{\#} \mathrm{p}<0.01$ compared with control. 
Table 3. Signaling molecules involved in Evodia rutaecarpa-induced hepatotoxicity.

\begin{tabular}{|c|c|c|c|c|c|c|c|}
\hline $\begin{array}{c}\text { Target } \\
\text { protein } \\
\text { name }\end{array}$ & Flag-control & $\begin{array}{c}\text { Globally } \\
\text { normalized } \\
\text { control }\end{array}$ & $\begin{array}{c}\text { Error } \\
\text { range } \\
\text { control (\%) }\end{array}$ & Flag-treatment & $\begin{array}{c}\text { Globally } \\
\text { normalized-treatment }\end{array}$ & $\begin{array}{c}\text { Error range } \\
\text { treatment } \\
(\%)\end{array}$ & $\begin{array}{c}\text { Z-ratio } \\
\text { (treatment, } \\
\text { control) }\end{array}$ \\
\hline $\mathrm{PKCb} 2$ & 0.0 & 817 & 69.56 & 0.0 & 1512 & 25.34 & 1.23 \\
\hline Erk1/2 & 0.0 & 5400 & 20.45 & 0.0 & 12971 & 0.75 & $1.75^{\#}$ \\
\hline $\mathrm{JNK} 1 / 2 / 3$ & 0.0 & 733 & 21.66 & 0.0 & 1319 & 63.20 & 1.17 \\
\hline JNK2 & 0.0 & 848 & 48.91 & 0.0 & 1512 & 54.17 & 1.16 \\
\hline S6Kb1 & 0.0 & 3540 & 70.09 & 0.0 & 5970 & 66.79 & 1.05 \\
\hline PAK2 & 0.0 & 2602 & 51.27 & 0.0 & 1178 & 67.24 & -1.52 \\
\hline $\operatorname{GSK} 3 \beta$ & 0.0 & 781 & 38.41 & 0.0 & 1257 & 33.24 & 0.96 \\
\hline Src & 0.0 & 1686 & 46.51 & 0.0 & 737 & 47.80 & $-1.60^{\#}$ \\
\hline CDK8 & 0.0 & 4675 & 34.94 & 0.0 & 905 & 9.00 & $-3.19^{\#}$ \\
\hline CK1e & 0.0 & 22363 & 15.41 & 0.0 & 11556 & 24.51 & $-1.26^{\#}$ \\
\hline AMPKb1 & 0.0 & 777 & 68.70 & 0.0 & 434 & 35.17 & -1.12 \\
\hline PTEN & 0.0 & 3849 & 4.71 & 0.0 & 5898 & 10.27 & 0.87 \\
\hline $\mathrm{NF} \kappa \mathrm{B}$ p50 & 0.0 & 1386 & 50.82 & 0.0 & 2722 & 0.13 & 1.35 \\
\hline $\mathrm{NF} \kappa \mathrm{B}$ p 65 & 0.0 & 3718 & 36.42 & 0.0 & 10879 & 94.73 & 2.13 \\
\hline $\mathrm{IKKb}$ & 0.0 & 609 & 83.04 & 0.0 & 951 & 62.20 & 0.90 \\
\hline PKA Cb & 0.0 & 431 & 6.80 & 0.0 & 911 & 10.21 & 1.49 \\
\hline
\end{tabular}

${ }^{\#}$ Concurrently meet these criteria, Z-ratio $\geq \pm 1.0, \%$ Error Range $\leq 50$, Globally Normalized Median Value $\geq 618$, Flags $=0.0$.

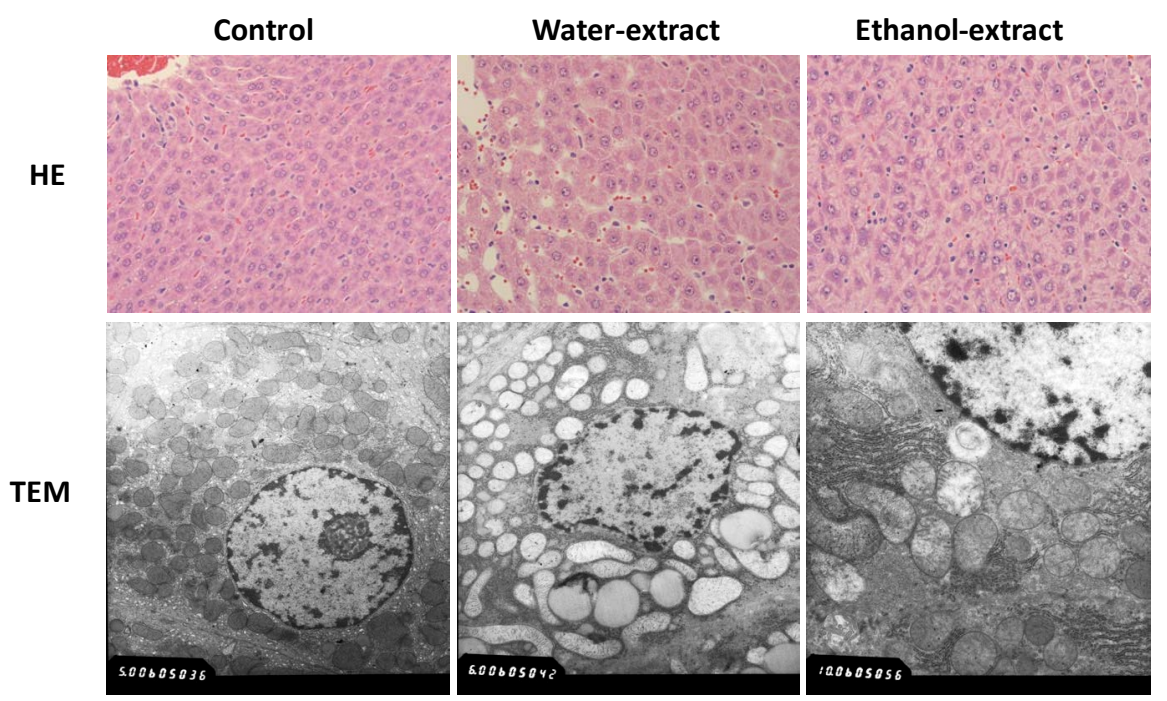

Figure 1. Evodia rutaecarpa-induced hepatotoxicity. Representative image of histological assay of liver tissues taken from mice subjected to either physiological saline (control) or intragastric administration of Evodia rutaecarpa extract (water- or ethanol-extract) once a day on 30 consecutive days at a dose equivalent to $16.67 \mathrm{~g}$ crude-drug $/ \mathrm{kg}$ body weight ( $\mathrm{n}=12$ per group). Liver tissue sections were stained with haematoxylin and eosin, observed using Leica Microscope. Swelling and degenerated hepatocytes and the infiltration of inflammatory cells were observed. Magnification: 20×. Under TEM detection, swelling mitochondria and lipid droplets in the cytoplasm observed in the Evodia rutaecarpa extract groups. Magnification: $10,000 \times$.

shown in Figure 3. Either water- or ethanol-extract of E.R. markedly increased the Erk1/2 and CDK8 phosphorylation, as well as the protein expression of $\mathrm{Ck} 1 \mathrm{e}$, but significantly inhibited the Src phosphorylation. These 

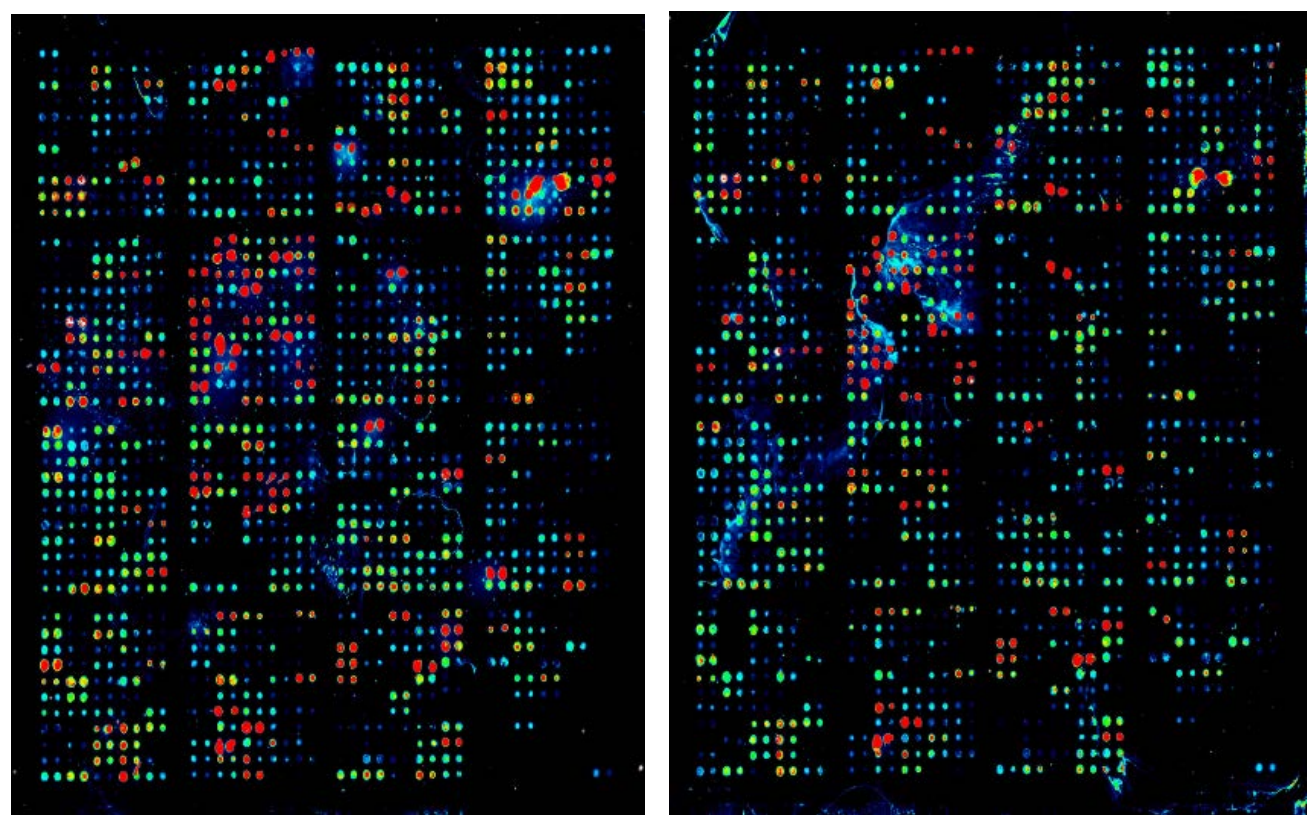

(a)

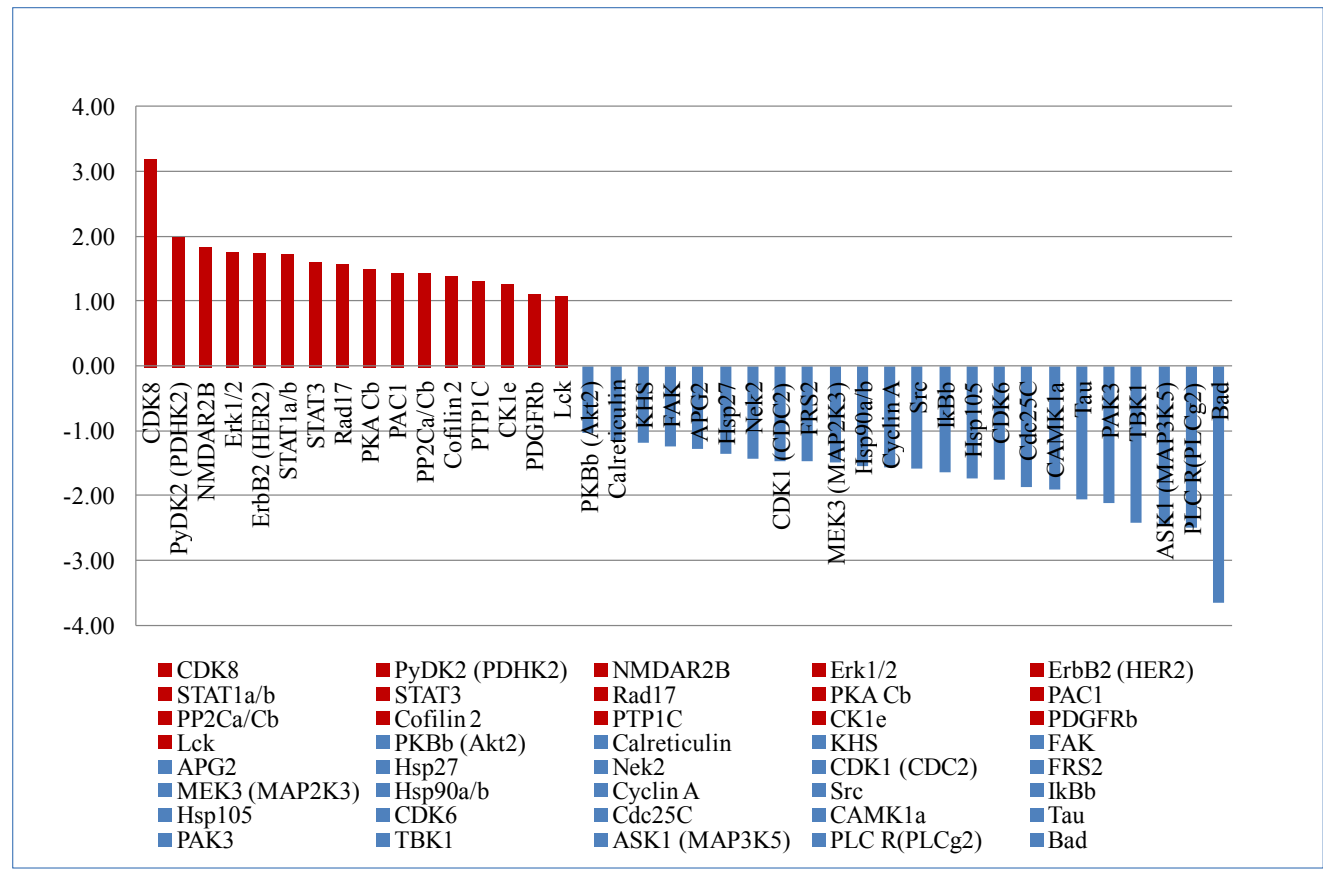

(b)

Figure 2. Cellular signaling molecules involved in Evodia rutaecarpa-induced hepatotoxicity. (a) Representative image of antibody microarray chip screened at $540 \mathrm{~nm}$ by Bio-Rad Vers Array Chip Reader. Green dots indicate decreased abundance and red dots indicate increased abundance. Dots with red and green combined represent no change. (b) Significantly changed proteins probably directly involved in Evodia rutaecarpa-induced hepatotoxicity. Forty signaling molecules among 854 molecules from Ingenuity Tox List Report were selected according to Kinexus criteria: Z-ratio $\geq \pm 1.0, \%$ Error Range $\leq 50$, Globally Normalized Median Value $\geq 618$, Flags $=0.0$. X-axis represents as different signaling molecules, $\mathrm{Y}$-axis as Z-ratio value. Antibody microarray chip was repeated two times with the same result.

data confirmed the result obtained from the antibody microarray chip and indicated that these signaling molecules, Erk1/2, CDK8, Ck1e and Src, are involved in the E.R.-induced hepatotoxicity. 


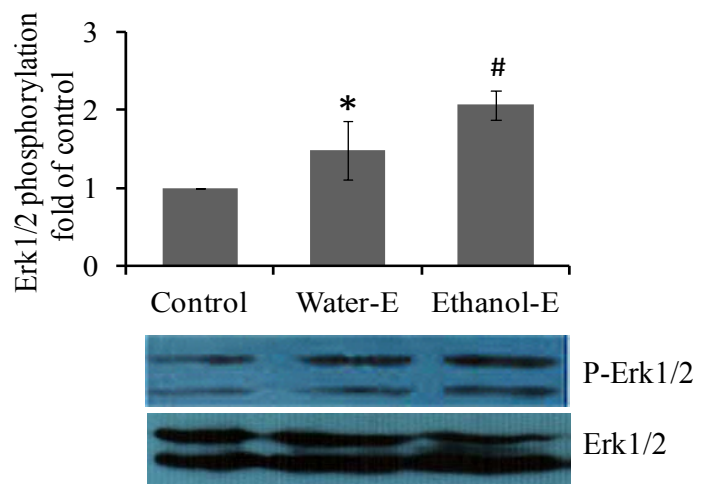

(a)

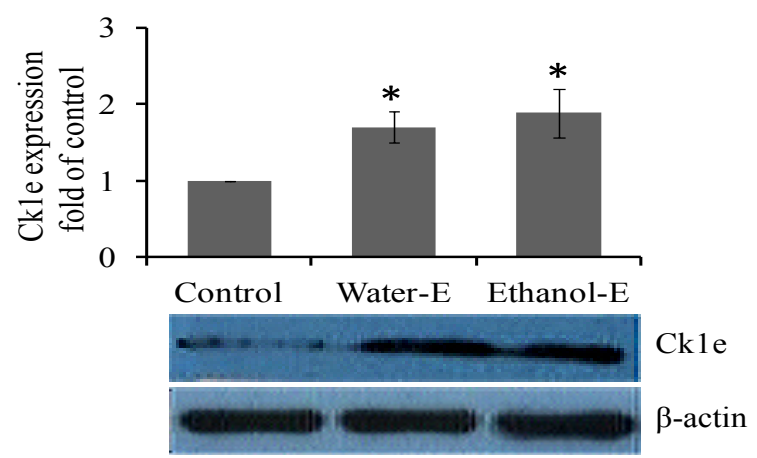

(c)

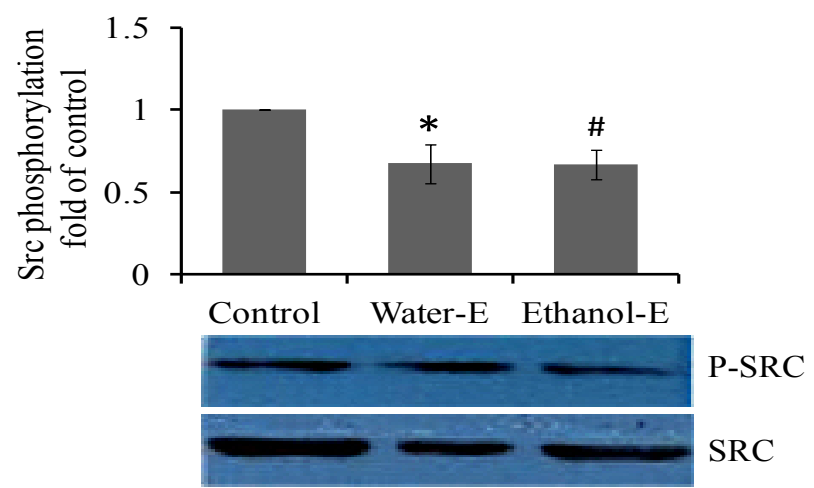

(b)

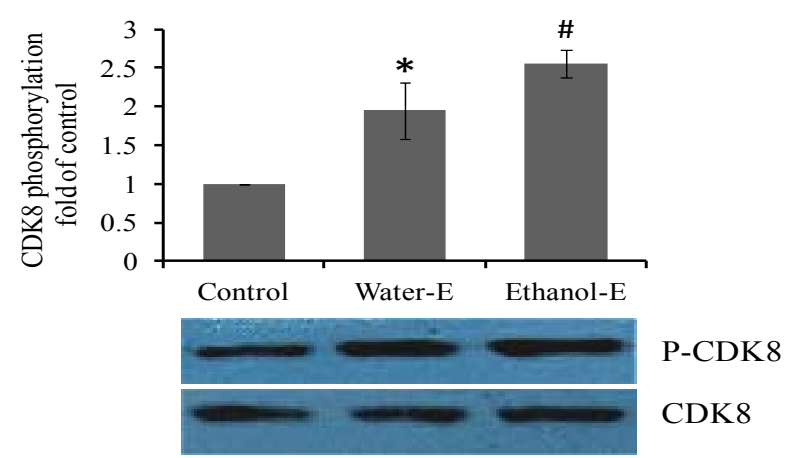

(d)

Figure 3. Validation of signaling molecules involved in Evodia rutaecarpa-induced hepatotoxicity by Western blotting. The whole tissue lysate was harvested in each group for Western blot analysis using the specific antibody for phospho-Erk1/2 (a), phospho-Src (b), phospho-CDK8 (d) and Ck1e (c), separately. The same membranes were stripped and re-probed with total Erk1/2, Src, CDK8 and $\beta$-actin antibody. The graphs indicate results of densitometric analysis and the data are the mean \pm S.E.M. $(n=4)$ and expressed as fold-change versus control. ${ }^{*} \mathrm{p}<0.05$ and ${ }^{\#} \mathrm{p}<0.01$ compared with control. Water-E represents as Evodia rutaecarpa water extract, Ethanol-E as Evodia rutaecarpa ethanol extract, Control as physiological saline group.

\subsection{E.R. Induces Liver Expression of IL-6, IL-8, IL-1 $\beta$, and TNF- $\alpha$}

CDK8, Ck1e and Src, which have been reported to be associated with the Wnt $/ \beta$-catenin pathway and Erk1/2 can regulate the expression of some inflammatory cytokines and interleukins, such as IL-6, IL-8, IL-1 $\beta$, and TNF- $\alpha$. Tissue injury is highly regulated by these inflammatory cytokines [15]-[17]. Therefore, the content of Il-6, Il-8, IL-1 $\beta$ and TNF- $\alpha$ in the liver tissues was measured by ELISA. As shown in Figure 4, the expression of these factors in the E.R. groups is much higher than that in the control group, indicating that these inflammatory cytokines and interleukins contribute to the hepatotoxicity induced by E.R..

\section{Discussion}

In the present study, liver was identified as a main organ injured by E.R., as manifested by increase on the liver index and serum levels of ALT and TG (Table 1 and Table 2), as well as by swelling/degenerated hepatocytes and swelling mitochondria and lipid droplets in the cytoplasm (Figure 1). The potential cellular signaling molecules involved in this process were detected through a high-throughput antibody microarray assay, and 4 molecules, Erk1/2, CDK8, Ck1e and Src, were screened out from among 854 molecules and further confirmed by western blotting (Figure 2 and Figure 3). In addition, the inflammatory cytokines, IL-1 $\beta$, IL-6, IL-8, and TNF- $\alpha$ in liver tissue were measured and probably mediate the E.R.-induced hepatotoxicity (Figure 4).

E.R., containing many active components, can act on different targets and exert various pharmacological effects, such as analgesic, cardiovascular and gastrointestinal protective, anti-obese, anti-inflammation, anti-infection and anti-cancer activities [3] [18]-[21]. In clinical practice, E.R. is the main component of Wuzhuyu 


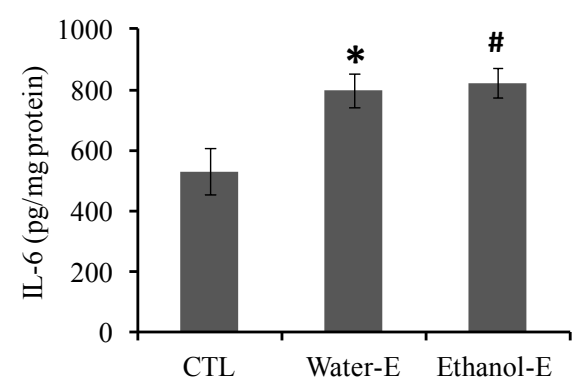

(a)

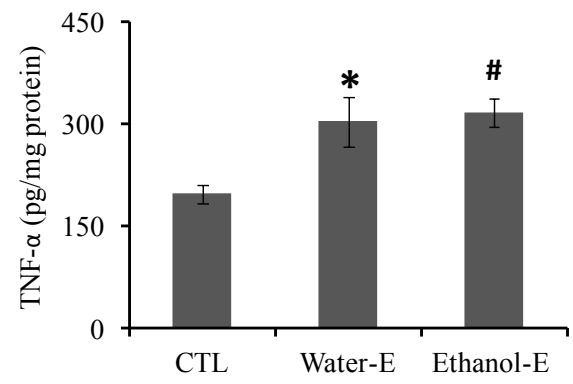

(c)

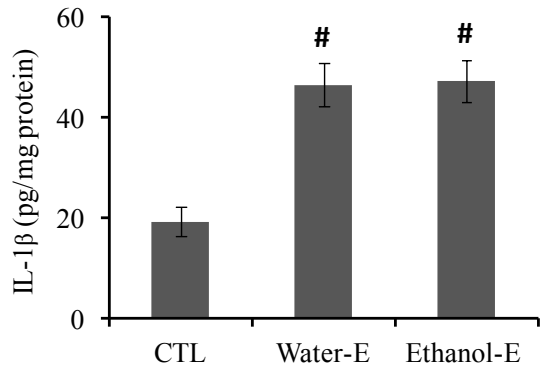

(b)

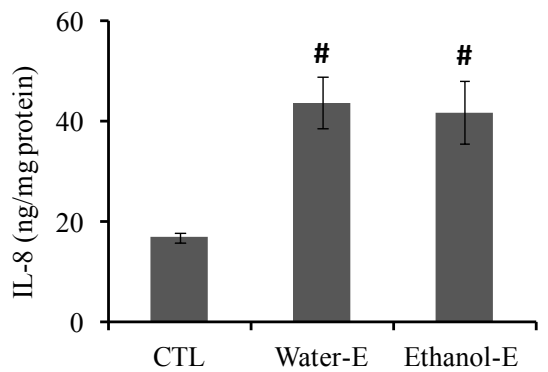

(d)

Figure 4. Evodia rutaecarpa induces liver expression of IL-6, IL-8, IL-1 $\beta$, and TNF- $\alpha$. Liver tissue homogenates were obtained from each group and the content of IL-6, IL- $1 \beta$, IL- 8 and TNF- $\alpha$ were measured by ELISA. The data are expressed as mean \pm S.E.M., $\mathrm{n}=4$ per group, ${ }^{*} \mathrm{p}<0.05$ and ${ }^{\#} \mathrm{p}<0.01$ compared with control. IL-6: interleukin-6; IL-1 $\beta$ : interleukin- $1 \beta$; IL-8: interleukin-8; TNF- $\alpha$ : tumor necrosis factor- $\alpha$.

Tang (Evodia prescription), which is a Chinese medicinal formula containing E.R., Ginger, Ginseng, and Jujube, and is commonly used for the treatment of headache, dizziness, and gastrointestinal diseases, such as chronic gastritis and vomiting [22]. In addition, E.R. is also used for digestion problems including diarrhea, dysentery, nausea, abdominal pain, gastroesophageal reflux disease, stomach ulcers, and lack of appetite, and for obesity, high blood pressure, congestive heart failure, infections caused by viruses, Alzheimer's disease, cancer, and fluid retention [23]. Though E.R. has various beneficial effects, some adverse effects should be given more attention. It has been suggested that E.R. exerts an anti-fertility effect and causes animals' uterus to contract and seems to reduce the size of their litters. E.R. should be avoided when breast-feeding or pregnant [24] [25]. Sheu et al. have reported that E.R. also has an effective anti-platelet action and seems to slow blood clotting. Thus, the risk of bleeding during and after surgery might be a concern [26]. Besides these side effects mentioned above, increasing evidence indicates that E.R. is associated with organ toxicity. Zhu et al. have reported that E.R. has nephro- and hepato-toxicities, can inhibit nephrocyte and hepatocelluar viability and can increase the serum level of AST, ALP and LDH [27]. In the present study, liver lesions were observed through H-E staining and TEM (Figure 1) and the liver index and serum level of ALT and TG were strongly increased (Table 1 and Table 2), indicating that E.R. can induce hepatotoxicity.

In general, viruses, drugs and toxic substances can induce hepatocelluar lesions, in which inflammatory factors including cytokines and complementary factors, e.g. TNF- $\alpha$, IL-1, IL- 6 , IL- 8 , are produced and induce hepatocelluar apoptosis and necrosis. 4 cellular signaling transduction pathways, TGF- $\beta /$ Smad, Wnt, mTOR, and $\mathrm{NF}$-B pathways, have been reported to be involved in the hepatotoxicity induced by many Chinese herbs and to mediate the production of various factors production followed by liver lesion [28]-[31].

In total 854 molecules were detected through the antibody microarray analysis used in this study. Four signaling molecules, Erk1/2, Src, CDK8 and CK1e, were selected out and verified by Western blotting as potential molecules involved in E.R.-induced hepatotoxicity. Either water extract or ethanol extract of E.R. can induce the phosphorylation of Erk1/2 and CDK8, increase the expression of CK1e, and inhibit Src phosphorylation.

Erk1/2 is a pivotal molecule in the TGF- $\beta /$ Smad and mTOR signal transduction pathways, as are CDK8, Ck1e and $\mathrm{Src}$ in the $\mathrm{Wnt} / \beta$-catenin pathway. Erk1/2 regulates transcriptional factors related to inflammation and apoptosis, which contribute to liver lesions. Cubero et al. has found that Erk1/2 phosphorylation mediated alcohol-induced liver injury by Kupffer cell activation and TNF- $\alpha$ production in rats [32]. Evodiamine, one of the compo- 
nents of E.R., can stimulate the phosphorylation of ERK1/2, and inhibit adipogenesis and provoke IL-8 secretion [22] [33]. In addition, E.R. can regulate the phosphorylation of Erk1/2 and inhibit the growth and metastasis of MDA-MB-231 human breast cancer cells in vitro and in vivo [34]. Taken together, in the present study, both water extract and ethanol extract of E.R. can increase Erk1/2 phosphorylation, which likely contributes to the hepatotoxicity induced by E.R.

The Wnt/ $\beta$-catenin pathway is an evolutionarily conserved and highly complex signaling cascade that is critical for development, differentiation and cellular homeostasis. Specifically, $\beta$-catenin, the central component of the canonical Wnt pathway, is implicated in the regulation of liver regeneration, development, and carcinogenesis, and thus plays a very important in liver metabolism and maintenance of normal function in the adult liver [35] [36]. In this study, we found that E.R. can induce the phosphorylation of CDK8, and increase Ck1e expression, while inhibits the phosphorylation of Src. These three molecules, CDK8, Ck1e and Src, are critical contributors to regulation of the $\beta$-catenin signaling pathway. CDK8 stimulates $\beta$-catenin activity either directly or via suppression of E2F1 and regulates $\beta$-catenin transcriptional activity [37]-[39]. Ck1e can directly maintain the stabilization of $\beta$-catenin and is a key activator of the $\beta$-catenin signaling pathway. The expression of Ck1e can promote oncogenic transformation of human cells in a $\beta$-catenin-dependent manner [40] [41]. Also, Src mediates the $\beta$-catenin signal transduction pathway, where $\beta$-catenin is phosphorylated at $\operatorname{Tyr}(654)$ by Src and activates the target transcription factors [42] [43]. We found that E.R. can induce the phosphorylation of CDK8, and increase the Ck1e expression, while inhibiting the phosphorylation of Src. Thus we speculate that $\beta$-catenin, as a downstream signaling molecule of CDK8, Ck1e and Src, mediates the process of hepatotoxicity induced by E.R.

Inflammatory factors including cytokines, chemokines and complementary factors, e.g. TNF- $\alpha$, IL-1, IL-6, IL-8, can directly trigger the inflammatory responses which result in the hepatotoxicity seen upon the treatment of drugs and toxic substances [44]-[46]. It has been reported that Evodia rutaecarpa extracts can stimulate the secretion of IL- $1 \beta$, IL-6, TNF- $\alpha$ and granulocyte-macrophage colony-stimulating factor in human mononuclear cells [47] [48]. As shown in Figure 4, in our study, the expression of IL-1 $\beta$, IL-6, IL-8 and TNF- $\alpha$ were significantly increased upon exposure to either water extract or ethanol extract of Evodia rutaecarpa.

Therefore, Evodia rutaecarpa-induced hepatotoxicity can most likely be attributed to inflammatory factors and cytokines which are regulated by the Erk $1 / 2$ and $\beta$-catenin signaling pathways. We propose the model showed in Figure 5 to depict Evodia rutaecarpa-induced hepatotoxicity in mice. Upon treatment with E.R. extract, Erk1/2

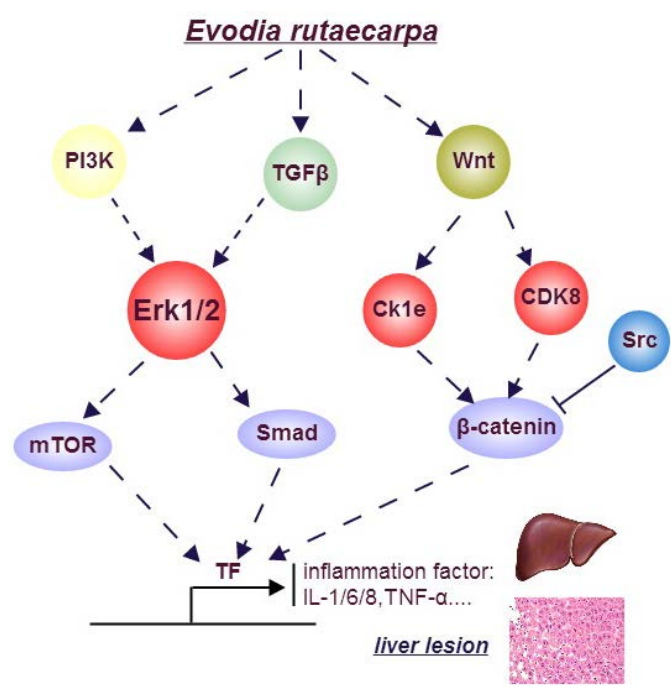

Figure 5. A presumable signaling pathway for Evodia rutaecarpa-induced hepatotoxicity in mice. Upon the treatment with Evodia rutaecarpa extract, Erk1/2 is phosphorylated and activated via either activated PI3K or TGF- $\beta$, and CDK8 is phosphorylated and activated and Ck1e expression was increased via the Wnt pathway. Activated Erk1/2 via mTOR and Smad, and $\mathrm{CDK} 8, \mathrm{Ck} 1 \mathrm{e}$ and Src via $\beta$-catenin lead to transcription factor activation and initiate gene transcription of inflammation factors, such as interleukin cytokines (IL)-1/6/8, and tumor necrosis factor (TNF)- $\alpha$, and result in liver lesion. Erk1/2, Extracellular signal-regulated kinases $1 / 2$; PI3K, phosphoinositide 3-kinase; TGF- $\beta$, transforming growth factor- $\beta$; CDK8, cyclin-dependent kinase 8; Ck1e, casein kinase 1 epsilon; mTOR, mammalian target of rapamycin; Src, v-src sarcoma (Schmidt Ruppin A-2) viral oncogene homolog. 
is phosphorylated and activated via either activated PI3K or TGF- $\beta$, CDK 8 is phosphorylated and activated, and Ck1e expression is increased via the Wnt pathway. Activated Erk1/2 via mTOR and Smad, and CDK8, Ck1e and Src via $\beta$-catenin lead to transcriptional factor activation and initiate transcription of inflammation factors, such as interleukin cytokines (IL)-1/6/8, and tumor necrosis factor (TNF)- $\alpha$, followed by liver lesion.

\section{Conclusion}

In summary, our findings established that the extract of E.R. could induce hepatotoxicity in mice. We have also shown that E.R. increases Erk1/2 and CDK8 phosphorylation, as well as the Ck1e expression, and inhibits the Src phosphorylation. These molecules probably induce IL- $1 \beta$, IL-6, IL- 8 and TNF- $\alpha$ expression, with ensuing liver pathology upon the treatment of E.R. Regulation of the TGF- $\beta /$ Erk/Smad, TGF- $\beta /$ Erk/mTOR, and CDK8/ $\mathrm{Ck} 1 \mathrm{e} / \mathrm{Src} / \beta$-catenin pathway is most likely involved in E.R.-induced hepatotoxicity.

\section{Acknowledgements}

This work was supported by grants of Science \& Technology Department of Sichuan Province (No. A-2011N22), partly by grants of the National Key Basic Research Plan (No. 2009CB522801) and by grants of the National Natural Fund Project (No. 81073047) in China. The authors cordially thank Dr. Nicholas J. Carruthers in Henry Ford Health System for his critical reading.

\section{References}

[1] Kobayashi, Y. (2003) The Nociceptive and Anti-Nociceptive Effects of Evodiamine from Fruits of Evodia rutaecarpa in Mice. Planta Medica, 69, 425-428. http://dx.doi.org/10.1055/s-2003-39701

[2] Moon, T.C., Murakami, M., Kudo, I., et al. (1999) A New Class of COX-2 Inhibitor, Rutaecarpine from Evodia rutaecarpa. Inflammation Research, 48, 621-625. http://dx.doi.org/10.1007/s000110050512

[3] Peng, J. and Li, Y.J. (2010) The Vanilloid Receptor TRPV1: Role in Cardiovascular and Gastrointestinal Protection. European Journal of Pharmacology, 627, 1-7. http://dx.doi.org/10.1016/j.ejphar.2009.10.053

[4] Wu, C.L., Hung, C.R., Chang, F.Y., et al. (2002) Effects of Evodiamine on Gastrointestinal Motility in Male Rats. European Journal of Pharmacology, 457, 169-176. http://dx.doi.org/10.1016/S0014-2999(02)02687-0

[5] Huang, X., Li, W. and Yang, X.W. (2012) New Cytotoxic Quinolone Alkaloids from Fruits of Evodia rutaecarpa. Fitoterapia, 83, 709-714. http://dx.doi.org/10.1016/j.fitote.2012.02.009

[6] Kima, D., Lee, Y.H., Park, S.H., et al. (2014) Subchronic Oral Toxicity of Evodia Fruit Powder in Rats. Journal of Ethnopharmacology, 151, 1072-1078. http://dx.doi.org/10.1016/j.jep.2013.12.006

[7] Hall, D., Ptacek, J. and Snyder, M. (2007) Protein Microarray Technology. Mechanisms of Ageing and Development, 128, 161-167. http://dx.doi.org/10.1016/j.mad.2006.11.021

[8] Morris, M.K., Chi, A., Melas, I.N., et al. (2013) Phosphoproteomics in Drug Discovery. Drug Discovery Today, 19, 425-432.

[9] Breitling, F., Nesterov, A., Stadler, V., et al. (2009) High-Density Peptide Arrays. Molecular BioSystems, 5, $224-234$. http://dx.doi.org/10.1039/b819850k

[10] Pierobon, M., VanMeter, A., Moroni, N., et al. (2012) Reverse-Phase Protein Microarrays. Methods in Molecular Biology, 823, 215-235. http://dx.doi.org/10.1007/978-1-60327-216-2_14

[11] Wildt, R.M., Mundy, C.R., Gorick, B.D. and Tomlinson, I.M. (2000) Antibody Arrays for High-Throughput Screening of Antibody-Antigen Interactions. Nature Biotechnology, 18, 989-994. http://dx.doi.org/10.1038/79494

[12] Cho, Y.E., Singh, T.S., Lee, H.C., Moon, P.G., Lee, J.E., Lee, M.H., et al. (2012) In-Depth Identification of Pathways Related to Cisplatin-Induced Hepatotoxicity through an Integrative Method Based on an Informatics-Assisted Label-Free Protein Quantitation and Microarray Gene Expression Approach. Molecular \& Cellular Proteomics, 11, Article ID: M111.010884.

[13] Cho, Y.E., Moon, P.G., Lee, J.E., Singh, T.S.K., Kang, W., Lee, H.-C., et al. (2013) Integrative Analysis of Proteomic and Transcriptomic Data for Identification of Pathways Related to Simvastatin-Induced Hepatotoxicity. Proteomics, 13, 1257-1275. http://dx.doi.org/10.1002/pmic.201200368

[14] Hu, Z.Y., Lausted, C., Yoo, H., Yan, X.W., Brightman, A., Chen, J.K., et al. (2014) Quantitative Liver-Specific Protein Fingerprint in Blood: A Signature for Hepatotoxicity. Theranostics, 4, 215-228. http://dx.doi.org/10.7150/thno.7868

[15] Bancerek, J., Poss, Z.C., Steinparzer, I., Sedlyarov, V., Pfaffenwimmer, T., Mikulic, I., et al. (2013) CDK8 Kinase 
Phosphorylates Transcription Factor STAT1 to Selectively Regulate the Interferon Response. Immunity, 38, $250-262$. http://dx.doi.org/10.1016/j.immuni.2012.10.017

[16] Gustafson, B. and Smith, U. (2006) Cytokines Promote Wnt Signaling and Inflammation and Impair the Normal Differentiation and Lipid Accumulation in 3T3-L1 Preadipocytes. The Journal of Biological Chemistry, 281, 9507-9516. http://dx.doi.org/10.1074/jbc.M512077200

[17] Hayashi, R., Yamashita, N., Matsui, S., Fujita, T., Araya, J., Sassa, K., et al. (2000) Bradykinin Stimulates IL-6 and IL-8 Production by Human Lung Fibroblasts through ERK- and p38 MAPK-Dependent Mechanisms. European Respiratory Journal, 16, 452-458. http://dx.doi.org/10.1034/j.1399-3003.2000.016003452.x

[18] Jiang, J.L. and Hu, C.P. (2009) Evodiamine: A Novel Anti-Cancer Alkaloid from Evodia rutaecarpa. Molecules, 14, 1852-1859. http://dx.doi.org/10.3390/molecules14051852

[19] Kobayashi, Y., Nakano, Y., Kizaki, M., Hoshikuma, K., Yokoo, Y. and Kamiya, T. (2001) Capsaicin-Like Anti-Obese Activities of Evodiamine from Fruits of Evodia rutaecarpa, a Vanilloid Receptor Agonist. Planta Medica, 67, 628-633. http://dx.doi.org/10.1055/s-2001-17353

[20] Wang, T., Wang, Y.X., Kontani, Y., Kobayashi, Y., Sato, Y., Mori, N. and Yamashita, H. (2008) Evodiamine Improves Diet-Induced Obesity in a Uncoupling Protein-1-Independent Manner: Involvement of Antiadipogenic Mechanism and Extracellularly Regulated Kinase/Mitogen-Activated Protein Kinase Signaling. Endocrinology, 149, 358366. http://dx.doi.org/10.1210/en.2007-0467

[21] Zhang, T., Qu, S., Shi, Q., He, D.L. and Jin, X.B. (2014) Evodiamine Induces Apoptosis and Enhances TRAIL-Induced Apoptosis in Human Bladder Cancer Cells through mTOR/S6K1-Mediated Downregulation of Mcl-1. International Journal of Molecular Sciences, 15, 3154-3171. http://dx.doi.org/10.3390/ijms15023154

[22] Wang, T., Wang, Y.X. and Yamashita, H. (2009) Evodiamine Inhibits Adipogenesis via the EGFR-PKC $\alpha$-ERK Signaling Pathway. FEBS Letters, 583, 3655-3659. http://dx.doi.org/10.1016/j.febslet.2009.10.046

[23] Liao, J.F., Chiou, W.F., Shen, Y.C., Wang, G.-J. and Chen, C.-F. (2011) Anti-Inflammatory and Anti-Infectious Effects of Evodia rutaecarpa (Wuzhuyu) and Its Major Bioactive Components. Chinese Medicine, 6, 6-15. http://dx.doi.org/10.1186/1749-8546-6-6

[24] Kong, Y.C., Hu, S.Y., Lau, F.K., Che, C.T., Yueng, H.W., Cheung, S. and Hwang, J.C.C. (1976) Potential Anti-Fertility Plants from Chinese Medicine. The American Journal of Chinese Medicine, 4, 105-128. http://dx.doi.org/10.1142/S0192415X76000160

[25] King, C.L., Kong, Y.C., Wong, N.S., Yeung, H.W., Fong, H.H.S. and Sankawa, U. (1980) Uterotonic Effect of Evodia rutaecarpa Alkaloids. Journal of Natural Products, 43, 577-582. http://dx.doi.org/10.1021/np50011a008

[26] Sheu, J.R., Hung, W.C., Wu, C.H., Lee, Y.M. and Yen, M.H. (2000) Antithrombotic Effect of Rutaecarpine, an Alkaloid Isolated from Evodia rutaecarpa, on Platelet Plug Formation in in Vivo Experiments. British Journal of Haematology, 110, 110-115. http://dx.doi.org/10.1046/j.1365-2141.2000.01953.x

[27] Zhu, L.I., Yang, D.X., Liu, X., Jia, F.-L., Ruan, M. and Zhang, B.-X. (2013) Hepatic Toxicity Study on the Fruit of Evodia rutaecarpa (Juss.) Benth. Lishizhen Medicine and Material Medical Research, 24, 1810-1813.

[28] Chou, C.C., Pan, S.L., Teng, C.M. and Guh, J.H. (2003) Pharmacological Evaluation of Several Major Ingredients of Chinese Herbal Medicines in Human Hepatoma Hep3B Cells. European Journal of Pharmaceutical Sciences, 19, 403412. http://dx.doi.org/10.1016/S0928-0987(03)00144-1

[29] LoPiccolo, J., Blumenthal, G., Bernstein, W. and Dennis, P. (2008) Targeting the PI3K/Akt/mTOR Pathway: Effective Combinations and Clinical Considerations. Drug Resistance Updates, 11, 32-50. http://dx.doi.org/10.1016/j.drup.2007.11.003

[30] Yuana, L.Y. and Kaplowitz, N. (2009) Glutathione in Liver Diseases and Hepatotoxicity. Molecular Aspects of Medicine, 30, 29-41. http://dx.doi.org/10.1016/j.mam.2008.08.003

[31] Yoon, J.Y., Jeong, H.Y., Kim, S.H., Kim, H.G., Nam, G., Kim, J.P., et al. (2013) Methanol Extract of Evodia lepta Displays Syk/Src-Targeted Anti-Inflammatory Activity. Journal of Ethnopharmacology, 148, 999-1007. http://dx.doi.org/10.1016/j.jep.2013.05.030

[32] Cubero, F.J. and Nieto, N. (2012) Arachidonic acid Stimulates TNF $\alpha$ Production in Kupffer Cells via a Reactive Oxygen Species-pERK1/2-Egr1-Dependent Mechanism. AJP: Gastrointestinal and Liver Physiology, 303, G228-G239. http://dx.doi.org/10.1152/ajpgi.00465.2011

[33] Shi, H.L., Wu, X.J., Liu, Y. and Xie, J.Q. (2013) Berberine Counteracts Enhanced IL-8 Expression of AGS Cells Induced by Evodiamine. Life Sciences, 93, 830-839. http://dx.doi.org/10.1016/j.1fs.2013.09.010

[34] Du, J., Wang, X.F., Zhou, Q.M., Zhang, T.L., Lu, Y.Y., Zhang, H. and Su, S.B. (2013) Evodiamine Induces Apoptosis and Inhibits Metastasis in MDA-MB-231 Human Breast Cancer Cells in Vitro and in Vivo. Oncology Reports, 30, 685694.

[35] Behari, J. (2010) The Wnt/ $\beta$-Catenin Signaling Pathway in Liver Biology and Disease. Expert Review of Gastroenter- 
ology \& Hepatology, 4, 745-756. http://dx.doi.org/10.1586/egh.10.74

[36] Lade, A.G. and Monga, S.P. (2011) Beta-Catenin Signaling in Hepatic Development and Progenitors: Which Way Does the WNT Blow? Developmental Dynamics, 240, 486-500. http://dx.doi.org/10.1002/dvdy.22522

[37] Firestein, R., Bass, A.J., Kim, S.Y., Dunn, I.F., Silver, S.J., Guney, I., et al. (2008) CDK8 Is a Colorectal Cancer Oncogene That Regulates $\beta$-Catenin Activity. Nature, 455, 547-551. http://dx.doi.org/10.1038/nature07179

[38] Firestein, R. and Hahn, W.C. (2009) Revving the Throttle on an Oncogene: CDK8 Takes the Driver Seat. Cancer Research, 69, 7899-7901. http://dx.doi.org/10.1158/0008-5472.CAN-09-1704

[39] Morris, E., Ji, J.Y., Yang, F., Di Stefano, L., Herr, A., Moon, N.S., et al. (2008) E2F1 Represses $\beta$-Catenin Transcription and Is Antagonized by both pRB and CDK8. Nature, 455, 552-556. http://dx.doi.org/10.1038/nature07310

[40] Kim, S.Y., Dunn, I.F., Firestein, R., Gupta, P., Wardwell, L., Repich, K., et al. (2010) CK1ع Is Required for Breast Cancers Dependent on $\beta$-Catenin Activity. PLoS ONE, 5, e8979. http://dx.doi.org/10.1371/journal.pone.0008979

[41] Bibiana, M., Rahaima, R.J., Choi, J.Y., Noguchi, Y., Schürer, S., Chen, W.M., et al. (2013) Development of Highly Selective Casein Kinase $1 \delta / 1 \varepsilon(\mathrm{CK} 1 \delta / \varepsilon)$ Inhibitors with Potent Antiproliferative Properties. Bioorganic \& Medicinal Chemistry Letters, 23, 4374-4380. http://dx.doi.org/10.1016/j.bmcl.2013.05.075

[42] Condello, S., Cao, L. and Matei, D. (2013) Tissue Transglutaminase Regulates $\beta$-Catenin Signaling through a C-SrcDependent Mechanism. The FASEB Journal, 27, 3100-3112. http://dx.doi.org/10.1096/fj.12-222620

[43] Hinck, L., Näthke, I.S., Papkoff, J. and Nelson, W.J. (1994) Beta-Catenin: A Common Target for the Regulation of Cell Adhesion by Wnt-1 and Src Signaling Pathways. Trends in Biochemical Sciences, 19, 538-542. http://dx.doi.org/10.1016/0968-0004(94)90057-4

[44] Bentli, R., Ciftci, O., Cetin, A., Unlu, M., Basak, N. and Cay, M. (2013) Oral Administration of Hesperidin, a Citrus Flavonone, in Rats Counteracts the Oxidative Stress, the Inflammatory Cytokine Production, and the Hepatotoxicity Induced by the Ingestion of 2,3,7,8-Tetrachlorodibenzo-p-dioxin (TCDD). European Cytokine Network, 24, 91-96.

[45] Jaeschke, H., Williams, C.D., Ramachandran, A. and Bajt, M.L. (2012) Acetaminophen Hepatotoxicity and Repair: The Role of Sterile Inflammation and Innate Immunity. Liver International, 32, 8-20. http://dx.doi.org/10.1111/j.1478-3231.2011.02501.x

[46] Saab, L., Peluso, J., Muller, C.D. and Ubeaud-Sequier, G. (2013) Implication of Hepatic Transporters (MDR1 and MRP2) in Inflammation-Associated Idiosyncratic Drug-Induced Hepatotoxicity Investigated by Microvolume Cytometry. Cytometry Part A, 83, 403-408. http://dx.doi.org/10.1002/cyto.a.22263

[47] Chang, C.P., Chang, J.Y., Wang, F.-Y., Tseng, J. and Chang, J.-G. (1995) The Effect of E.R. Extract on Cytokine Secretion by Human Mononuclear Cells in Vitro. The American Journal of Chinese Medicine, 23, 173-180. http://dx.doi.org/10.1142/S0192415X95000237

[48] Chang, J.Y., Yang, T.Y., Chang, C.P. and Chang, J.G. (1996) The Effect of “Chi-Han (Hot Nature)" Chinese Herbs on the Secretion of IL-1 Beta and TNF-Alpha by Mononuclear Cells. Journal of Medical Sciences, 12, 8-24. 